\title{
O VOTO NO DIREITO BRASILEIRO: História, Problemas e Propostas de Mudança
}

http://dx.doi.org/10.21527/2176-6622.2019.52.143-156

Recebido em: 3/1/2019

Modificações requeridas em: 19/7/2019

Aceito em: 22/7/2019

\section{Lucas Catib De Laurentiis}

Professor titular da PUC-Campinas. Coordenador e membro do corpo docente permanente do Programa de Pós-Graduação Stricto Sensu em Direito (PPGD), vinculado à linha de pesquisa \&quot;Cooperação Internacional e Direitos Humanos\&quot;. Doutorado e Mestrado em Direito Constitucional pela Faculdade de Direito da Universidade de São Paulo. Especialista em Direito Constitucional pela Pontifícia Universidade Católica de São Paulo. Advogado e consultor nas áreas de Direito Público e Direito Tributário. http://lattes.cnpq.br/2294492760875997 lucas.laurentiis@gmail.com

\section{Yohanan David Azevedo Bianchi}

Graduação em Direito pela Pontifícia Universidade Católica de Campinas, Brasil (2017). http://lattes.cnpq.br/8060432339243632. yohabianchi@icloud.com

\section{RESUMO}

O presente artigo discute o sistema eleitoral brasileiro no Estado Democrático de Direito e o voto obrigatório dentro deste sistema, levantando hipóteses a serem respondidas no decorrer da pesquisa. O método utilizado é o descritivo analítico, por meio do qual as conclusões do trabalho são extraídas de premissas históricas e dogmáticas retiradas do Direito Positivo brasileiro. Nesse sentido, faz-se necessário um estudo histórico dos sistemas eleitorais e do voto, bem como suas origens, fundamentos, finalidades, limites e conceito atual. Será igualmente apresentado um estudo do Direito comparado, por meio do qual o sistema eleitoral brasileiro e o direito ao voto no Brasil serão confrontados com modelos de sistemas eleitorais de outros países. Ao final, o trabalho será concluído com a análise de propostas legislativas que buscam alterar a configuração do direito ao voto no Direito brasileiro. 0 estudo analisa essas propostas e apresenta respostas aos questionamentos jurídicos delas decorrentes.

Palavras-chave: Direito eleitoral. Voto obrigatório. Sistemas eleitorais. Soberania popular. Cidadania.

\section{THE VOTE IN BRAZILIAN LAW: HISTORY, PROBLEMS AND PROPOSALS OF CHANGE}

\section{ABSTRACT}

This paper discusses the Brazilian electoral system in the Democratic State of Law and the mandatory voting with exists within this system, raising hypotheses to be answered in the course of the research. The research method used is the analytical descriptive, through which the conclusions of the work are taken from historical and dogmatic premises derived from Brazilian positive law. In this sense, it is necessary to develop a historical study of the electoral systems and the vote as well as its origins, foundations, purposes, limits and current concept. It will also be presented a study of comparative law, through which the Brazilian electoral system and the right to vote in Brazil will be confronted with models of electoral systems in other countries. In the end, the work will conclude with the analysis of legislative proposals that seek to change the configuration of the right to vote in Brazilian law. The paper analyzes these proposals and presents answers to the legal questions arising from them.

Keywords: Electoral law. Compulsory vote. Electoral systems. Popular sovereignty. Citizenship.

\section{SUMÁRIO}

1 Introdução. 2 Voto no Direito Comparado. 2.1 O Voto no Sistema Eleitoral dos Estados Unidos da América. 2.1 O Voto no Sistema Eleitoral Alemão. 2.3 O Voto no Sistema Eleitoral Argentino. 3 O Sistema Eleitoral Brasileiro: Histórico e Características Atuais. 3.1 Origem Histórica do Sistema Eleitoral Brasileiro. 3.1.1 Sistema Eleitoral do Período Imperial Brasileiro. 3.1.2 Sistema Eleitoral da Primeira República Brasileira. 3.1.3 As Mudanças no Sistema Eleitoral na Era Vargas. 3.2 Conceito e Características do Sistema Eleitoral. 3.3 Previsão Constitucional do Sistema Eleitoral Brasileiro. 3.4 O Problema do Voto Obrigatório. 3.4.1 A Obrigatoriedade e sua Coercibilidade. 3.5 Voto Obrigatório e Cláusulas Pétreas. 3.6 Uma Proposta de Instituição do Voto Facultativo. 4 Conclusões. 5 Referências. 


\section{INTRODUÇÃO}

O presente trabalho tem como seu objetivo central discutir o voto obrigatório de maneira ampla, seu conceito, limites e formas de atuação, e principalmente a forma como este se manifesta nas eleições brasileiras. Além disso, o texto analisa propostas legislativas que propõem a alteração da configuração do direito ao voto, tal qual regido pela Constituição Federal de 1988. Nesse sentido, o voto no Brasil será analisado sob diversos aspectos constitucionais e legais. Com base na comparação de modelos adotados em outros países, serão também indicadas algumas perspectivas de aprimoramento do sistema político brasileiro.

A análise aqui desenvolvida é descritiva analítica, método por meio do qual são fixadas as premissas da hipótese teórica a ser testada com base em uma exposição histórico-evolutiva do tema em debate. Com base nessas premissas, o trabalho apresenta soluções jurídico-dogmáticas para problemas práticos encontrados no sistema eleitoral brasileiro. Nesse sentido, a análise tem início com a exposição dos sistemas eleitorais brasileiros e busca, com isso, determinar a função de desempenho do voto. Com base nesse raciocínio, as diversas características do sistema eleitoral brasileiro são analisadas e confrontadas com modelos existentes em outros países. Ao final, serão também debatidas algumas propostas legislativas que pretendem alterar a configuração do direito ao voto no Brasil. Essas propostas serão avaliadas no que diz respeito à sua operacionalidade $e$ constitucionalidade. $O$ presente trabalho não tem a pretensão de esgotar o tema ou trazer uma resposta cabal acerca das questões aqui abordadas, mas pretende ao fim analisar e criar reflexões mais profundas a respeito dos problemas e possíveis soluções para o atual modelo eleitoral brasileiro.

\section{VOTO NO DIREITO COMPARADO}

O sistema jurídico brasileiro foi construído com base em diversas influências estrangeiras, muitas delas decorrentes de estreitamento diplomático, influências jurídicas, proximidade territorial e relações comerciais. As decorrências diretas de tais influências múltiplas são a complexidade do modelo estatal adotado pela Constituição Federal de 1988, que combina conceitos e influências europeias a um sistema de controle de ações estatais de tipo marcadamente norte-americano. ${ }^{1}$

Com o sistema eleitoral ocorre algo semelhante, pois nos diversos níveis do federalismo brasileiro são previstas formas variadas de eleição de representantes políticos, ora indicados pela sistemática majoritária simples, ora pela maioria absoluta e, enfim, pelo sistema proporcional. De toda forma, para efeitos classificatórios, é possível dizer que o Brasil adota a forma de Estado federativa, o Regime republicano e o sistema de governo presidencialista. Para que as características e especificidades deste modelo sejam devidamente compreendidas, é necessário que se realize uma análise de comparação entre o sistema eleitoral brasileiro e o de outros países, bem como sua forma de organização interna e o efetivo respeito aos direitos fundamentais.

\subsection{O Voto no Sistema Eleitoral dos Estados Unidos da América}

Os Estados Unidos da América possuem uma das Constituições mais antigas ainda em vigor. Promulgada em 1788, a Constituição Americana estabeleceu inicialmente a Forma de Estado Federalista, o Sistema de Governo Presidencialista, a separação dos poderes e a forma de realização das eleições. Não obstante, houve modificações, também chamadas de emendas constitucionais, que adicionaram a proteção aos direitos individuais e coletivos e restrições aos poderes inerentes ao governo.

Diferentemente do Brasil, os Estados Unidos da América possuem um sistema eleitoral diferenciado, em que as eleições para o poder Legislativo são realizadas diretamente pelo povo, de forma direta, e as eleições presidenciais são realizadas por meio dos chamados "eleitores", de forma indireta. ${ }^{2}$ Cria-se, com isso, uma potencial discrepância na forma de se realizar as eleições e o possível "peso" do voto nas eleições para

\footnotetext{
1 Para uma análise comparativa das Constituições brasileiras em relação a outros modelos constitucionais, conferir: FERREIRA, 1971, p. 108 et seq.; BONAVIDES, 2003, p. 362.

2 Para a fundamentação e exposição do funcionamento de tal sistemática eleitoral, ver: HAMILTON; MADISON; JAY, 2009 , p. 75.
} 
o mais alto cargo do poder Executivo. ${ }^{3}$ Dita forma de escolha e o número de eleitores estão definidos no artigo II, seção 1 da Constituição Americana: "Cada Estado nomeará, de acordo com as regras estabelecidas por sua Legislatura, um número de eleitores igual ao número total de senadores e deputados a que tem direito no Congresso; todavia, nenhum senador, deputado, ou pessoa que ocupe um cargo federal remunerado ou honorífico poderá ser nomeado eleitor... Os eleitores reunir-se-ão em seus respetivos Estados e votarão em escrutínio". ${ }^{4}$

As eleições presidenciais dos Estados Unidos da América são, portanto, realizadas de forma indireta, pois os eleitores são escolhidos pelo povo, por meio do voto facultativo, para votarem nos candidatos existentes ao cargo de presidente. Ressalta-se que inicialmente os eleitores não possuíam vinculações partidárias e estavam livres para votar, mas tal estigma inicial encontra-se superado, visto que hoje os eleitores possuem laços partidários em virtude de serem eles eleitos por uma chapa estabelecida por um determinado partido. Com fundamento em tais constatações, Bernard Schwartz extrai as seguintes conclusões:

Os eleitores presidenciais, há mais de um século, vêm votando nos candidatos do partido político em cuja chapa foram eleitos. Em muitos estados, realmente, nem aparecem na cédula os nomes dos eleitores, e os votantes votam somente no partido do candidato presidencial que eles preferem. É verdade que, em teoria, os eleitores ainda mantêm o seu arbítrio constitucional de votar em qualquer pessoa que escolham. Na prática, porém, o poder dos eleitores nesse particular é tão destituído de sentido quanto muitas das prerrogativas que, em teoria, a Coroa britânica ainda possui (1966, p. 119).

Desta maneira, surgiu o princípio que rege a eleição norte-americana: "vencedor leva tudo", o que indica que a chapa vitoriosa de eleitores em um Estado votará integralmente no candidato de seu partido. Para ilustrar tal orientação, observe-se a seguinte situação hipotética: em uma eleição presidencial, um dos Estados federados possui 30 eleitores, os quais devem ser eleitos pelo voto popular, e 1 milhão de cidadãos votantes. Neste contexto, o partido A e o partido B apresentaram a sua chapa de 30 eleitores presidenciais e aguardaram a apuração das eleições. Os votos resultantes foram contabilizados e totalizaram 499.000 votos para o partido A e 501.000 votos a favor do partido B. O resultado final foi: vence o partido B por diferença de 1.000 votos, mas como os votos do distrito não podem ser divididos de forma proporcional, é preciso atribuir ao partido B os 30 votos ao seu candidato presidencial, respectivamente. Suponha-se agora que existam outros dois distritos com 800 mil eleitores e 12 delegados cada. Mesmo que o partido A vença nestes dois distritos, obtendo em cada um deles 750 mil votos, o número de delegados a seu favor no colégio eleitoral será inferior ao que apoia a eleição do partido $B$, mesmo que a quantidade de votos dos cidadãos a favor do partido $B$ (601.000) seja muito inferior às depositadas no partido A (1.899.000).

Com essa pequena amostra, é clara a possibilidade de vitória de um presidente sem obter a maioria dos votos populares, mas sim a maioria dos eleitores do chamado Colégio Eleitoral. Essa forma indireta de votação é estritamente contraposta ao sistema eleitoral brasileiro, no qual a soberania popular nas eleições presidenciais é essencial para a vitória de um candidato, pois, conforme será demonstrado adiante, o Brasil adota o sistema majoritário para os cargos do poder Executivo e o voto é obrigatório.

Em contrapartida, há nos dois países igualdade no que diz respeito à defesa dos direitos dos cidadãos e o seu livre direito de votar, inclusive no período de mandato de quatro anos do presidente, e na exigência de naturalidade originária do candidato à Presidência, assim como em se exigir dele a idade mínima 35 anos e, enfim, a possibilidade de uma recondução.

\footnotetext{
Por isso, em seus comentários a tal dispositivo, observou Edward Corwin que "embora Madison houvesse testemunhado que o sistema de votação pelos distritos fora o tencionado pelos elaboradores da Constituição, os eleitores são hoje universalmente escolhidos pelo voto popular, em cédulas gerais para todo o Estado. O resultado é que o candidato vitorioso pode alcançar consideravelmente menos que uma maioria, ou até mesmo uma pluralidade do voto popular" (CORWIN, 1978, p. 115).

4 Lê-se no original: "Each State shall appoint, in such Manner as the Legislature thereof may direct, a Number of Electors, equal to the whole Number of Senators and Representatives to which the State may be entitled in the Congress: but no Senator or Representative, or Person holding an Office of Trust or Profit under the United States, shall be appointed an Elector. The Electors shall meet in their respective States, and vote by Ballot" (traduzido livremente).
} 


\subsection{Voto no Sistema Eleitoral Alemão}

A Alemanha possui imensas diferenças em seu sistema interno e a maneira de escolha de seus candidatos em comparação com o Brasil. A primeira e mais óbvia diferença está na própria definição do sistema de governo, que no caso alemão é parlamentarista. Os membros do Parlamento alemão (Bundestag) são os responsáveis por eleger o chanceler federal, chefe de governo alemão, por meio de votação de maioria simples, para mandato de quatro anos e sem restrições quanto ao número de reconduções. ${ }^{5}$

Atualmente, o Parlamento alemão possui 709 membros, com número mínimo de 598 assentos, sendo este número variável conforme as eleições realizadas. O sistema eleitoral alemão é razoavelmente complexo: nele cada cidadão tem direito a votar duas vezes, com o voto sendo um direito facultativo. Conforme explicado por Luís Virgílio Afonso da Silva:

(a) Cada Estado federado é divido em um número de distritos igual à metade das cadeiras a que tem direito no Parlamento; (b) cada partido apresenta dois tipos de candidaturas: um candidato para concorrer à eleição majoritária uninominal no interior de cada um dos vários distritos e uma lista de candidatos com ordem previamente definida pelo partido (lista bloqueada), igual para todos os distritos de um determinado Estado (lista estadual); (c) cada eleitor dispõe de dois votos, referentes às duas formas de candidaturas: no primeiro deles, vota no candidato do seu distrito e, no segundo, em uma das listas partidárias. (d) para o cálculo do número de cadeiras a que cada partido terá direito, são utilizados somente os segundos votos, ou seja, os votos dados para a lista partidária (1999, p. 81).

São, portanto, duas votações. A primeira com base no método majoritário, a segunda, com base no sistema proporcional. Após a apuração dos resultados, o número de cadeiras do Parlamento será dividido em função do quociente partidário, determinado pela fórmula proporcional Hare-Niemeyer. Possuirá o direito às cadeiras na proporção da porcentagem de votos obtidos na eleição da lista partidária e o número de assentos obtidos pelo partido com base na primeira votação (majoritária) são deduzidos do total de cadeiras determinado pela votação proporcional. ${ }^{6}$ Isso, contudo, não exclui a possibilidade de um determinado partido eleger na primeira votação um número de deputados superior ao determinado pela segunda votação, caso em que a lei eleitoral alemã admite a figura dos mandatos suplementares (Überhangmandat), o que gera a necessidade de se subtrair o número de cadeiras excedentes do total obtido pelos demais partidos. Contestada perante a Justiça Constitucional alemã, por ser vista como uma perversão do sistema proporcional alemão, essa prática foi considerada constitucional pelo Tribunal Constitucional Alemão. ${ }^{7}$

Outra característica existente no sistema eleitoral alemão é a cláusula de barreira existente para acesso às cadeiras do Parlamento, em que apenas os partidos que obtiverem $5 \%$ dos votos válidos nas eleições de lista podem ter representantes na Casa Legislativa. Esta cláusula-barreira visa a impedir a ascensão ao Bundestag de partidos considerados ínfimos, sob a afirmação de que poderiam causar uma quebra política extrema e criar dificuldades para a governabilidade. Como exemplo do impedimento de participação nos assentos por motivo de não atingir o percentual mínimo, o Partido do Bem-Estar Animal obteve $0,8 \%$ dos votos válidos nas eleições para o parlamento do ano de 2017 e foi impedido de possuir representantes. ${ }^{8}$

\footnotetext{
Descrevendo o modo de indicação de deposição do chanceler alemão, observou Jorge Miranda que "o governo, composto pelo chanceler e por ministros de sua escolha, passa a ser responsável perante a Assembleia nacional. É a esta que, sob proposta do presidente da República, compete eleger o chanceler (art. 63); e se lhe manifestar desconfiança, ele terá de ser substituído (art. 67). No entanto, a censura ao chanceler deverá ser acompanhada da indicação do seu sucessor" (MIRANDA, 2007, p. 125).

6 Nesse sentido, ver: HESSE, 1998, p. 442.

BVerfGE 95, 335. Por isso, é de se duvidar da correção da tese defendida por Virgílio Afonso da Silva, que sustenta que o sistema eleitoral alemão é pura e simplesmente proporcional. Para esse autor, a esmagadora maioria dos autores alemães considera que o sistema alemão não é misto, pois o número de cadeiras é determinado pelo critério proporcional. Esse mesmo autor, contudo, cita as palavras de Hans Meyer, para quem o sistema alemão é proporcional, com a peculiaridade de que a metade dos assentos obtidos pela sistemática proporcional é preenchida com base no critério majoritário (SILVA, 1999, p. 83). Se esta peculiaridade existe, porém, isso quer dizer que o sistema eleitoral alemão não é proporcional pura e simplesmente. Tal conclusão é reforçada pela previsão legislativa que determina a distribuição dos mandatos excedentes. Mesmo que no plano da teoria constitucional tal instrumento seja polêmico, na prática sua constitucionalidade foi confirmada pelo Tribunal Constitucional, o que faz com que de fato o sistema eleitoral alemão seja misto, vez que utiliza simultaneamente duas regras decisórias para a distribuição das cadeiras no parlamento.

\& Tierschutzpartei (livremente traduzido pelo autor).
} 


\section{$2.3 \mathrm{O}$ Voto no Sistema Eleitoral Argentino}

Na República Argentina vige ainda a Constituição de Santa Fé de 1853, texto que sofreu diversas modificações, a última delas operada no ano de 1994 (CASIELLO, 1954, p. 89). As regras eleitorais daquele país são muito próximas às adotadas no Brasil, tanto no que diz respeito à representatividade, como à forma da eleição, mas existem também algumas particularidades.

As eleições são divididas entre as eleições para presidente e as eleições para as Casas Legislativas. 0 sistema eleitoral adotado é diferente em cada uma delas. Na eleição para presidente da Nação Argentina exige-se do candidato ter nascido no território argentino ou que possua nacionalidade originária. O mandato é de quatro anos e essa eleição segue o sistema eleitoral majoritário de duas voltas - também chamado de dois turnos.

A particularidade encontrada nas eleições para presidente é a porcentagem necessária para ser considerado eleito o novo presidente: a chapa que obtiver $45 \%$ dos votos válidos na primeira volta será proclamada vencedora e seus candidatos para presidente e vice-presidente, eleitos. Quando a chapa mais votada na primeira volta obtiver pelo menos $40 \%$ dos votos válidos e existir uma diferença maior do que $10 \%$ do total dos votos válidos para o segundo colocado, os integrantes da chapa também são considerados eleitos. ${ }^{9}$

Um dos pontos interessantes nas eleições presidenciais é a inexistência da inelegibilidade reflexa na reeleição. Ou seja, não há o impedimento de parentes se elegerem para o mesmo cargo após o último mandato possível do detentor do mandato eletivo. Justamente por isso, por diversos anos a Presidência da República argentina foi dominada pela família Kirchner.

A votação para a composição das duas Casas Legislativas argentinas também se aproxima da existente no Brasil: segue o sistema eleitoral proporcional de escolha dos candidatos, mas não se assemelha na escolha direta dos candidatos pelos eleitores. O objetivo do sistema proporcional argentino, chamado de representação proporcional, é favorecedor do multipartidarismo em um mundo eleitoral de dimensões grandes, pois quanto maior a disputa eleitoral, melhor a representatividade proporcional e efetiva dos anseios populares. Os detentores de mandatos eletivos para o poder Legislativo Federal Argentino são renovados em sua metade a cada dois anos, por meio das eleições proporcionais, em que os partidos apresentam listas com os respectivos candidatos, como observa Juan Vicente Sola:

As listas dos partidos podem ser fechadas, quando os candidatos são eleitos em uma ordem determinada pelo próprio partido; ou abertas, quando os candidatos são apresentados pelos partidos em uma ordem determinada, mas os eleitores possuem a possibilidade de manifestar uma preferência ou mais, mudando a ordem dos nomes e adicionando nomes de outras listas (2010, p. 509). ${ }^{10}$

Com essa possibilidade, os partidos têm a faculdade de escolher entre a lista fechada e aberta, abrindo as possibilidades aos eleitores ou restringindo apenas para os seus próprios candidatos. Mesmo com a busca da efetivação da soberania popular, a Argentina ainda mantém o voto obrigatório em seu sistema democrático e nas eleições, uma possível contradição a ser tematizada adiante.

\section{O SISTEMA ELEITORAL BRASILEIRO: HISTÓRICO E CARACTERÍSTICAS ATUAIS}

Com a criação dos cargos eletivos, que são o instrumento por excelência da efetivação da representação partidária, faz-se necessário criar uma sistemática para a indicação dos representantes eleitos. ${ }^{11}$ Para tanto, os esforços são direcionados no sentido da sistematização e normatização de técnicas e procedimentos para alinhar a vontade dos cidadãos e sua conversão em mandatos eletivos políticos.

\footnotetext{
9 Artículo 97 de la Constituición argentina: Cuando la fórmula que resultare más votada en la primera vuelta, hubiere obtenido más del cuarenta y cinco por ciento de los votos afirmativos válidamente emitidos, sus integrantes serán proclamados como presidente y vicepresidente de la Nación. Artículo 98: Cuando la fórmula que resultare más votada en la primera vuelta hubiere obtenido el cuarenta por ciento por lo menos de los votos afirmativos válidamente emitidos y, además, existiere una diferencia mayor de diez puntos porcentuales respecto del total de los votos afirmativos válidamente emitidos sobre la fórmula que le sigue en número de votos, sus integrantes serán proclamados como presidente y vice-presidente de la Nación.

10 No original: Las listas de los partidos pueden ser cerradas, cuando los candidatos son electos en el orden determinado por el partido; o abiertas, cuando los candidatos son presentados por los partidos en un orden determinado pero los electores tienen la posibilidad de manifestar una preferencia o más, cambiando el orden de los nombres o agregando nombres de otras listas (livremente traduzido).

${ }^{11}$ A esse respeito, ver: LAURENTIIS, 2011.
} 


\section{Debate}

Tal sistematização e normatização é chamada de sistema eleitoral. Sua finalidade é a adequação das eleições por meio de um sistema confiável, eficaz e a existência de transparência. Os principais sistemas eleitorais presentes no Brasil são: majoritário simples, majoritário absoluto e proporcional, e suas variações serão apresentadas conforme a aplicação. Os sistemas eleitorais possuem mutabilidade ao longo do tempo, momento em que não há de se falar em sistema eleitoral perfeito, mas sim em adequação e evolução histórica dos sistemas eleitorais perpetuados no Brasil.

\subsection{Origem Histórica do Sistema Eleitoral Brasileiro}

Para que possamos entender a feição que o sistema eleitoral brasileiro possui na contemporaneidade é necessário remontar ao surgimento do Direito Constitucional brasileiro e apresentar a sua mutabilidade e evoluções ao longo dos anos. Cumpre salientar que o estudo do sistema eleitoral brasileiro remonta ao período imperial, dado que o Brasil Colônia não possuía seu próprio sistema eleitoral em virtude da imposição exploradora de Portugal sobre as terras brasileiras, bem como a aplicação da Monarquia e de suas leis dominantes.

\subsubsection{Sistema Eleitoral do Período Imperial Brasileiro}

Após a outorga da Constituição de 25 de março de 1824 por Dom Pedro I, surge o primeiro sistema eleitoral brasileiro constitucionalizado e a divisão dos poderes políticos. Tem-se essa divisão em: poder Legislativo, poder Moderador, poder Executivo e o poder Judicial. A escolha por meio de votos, conforme expressamente continha a Constituição de 1824 , seria dos cargos políticos do poder Legislativo, composta por deputados eleitos para mandatos de 4 anos e senadores, com mandatos vitalícios da Assembleia Geral - composta pela Câmara dos Deputados e Câmara dos Senadores, ou Senado - e dos membros dos Conselhos Gerais das Províncias. As eleições eram realizadas de forma indireta.

Depreende-se da análise do texto constitucional imperial a existência da divisão da eleição em dois graus, chamadas de eleições primárias e eleições de província. As eleições primárias (ou de 1o grau) eram compostas por eleitores considerados cidadãos ativos que escolheriam os eleitores das eleições de província. Para serem considerados eleitores de primeiro grau, deveriam preencher certos requisitos e não poderiam ser enquadrados em determinadas hipóteses de impedimento contidas na Constituição de $1824 .{ }^{12} \mathrm{O}$ voto era censitário, pois apenas aqueles cidadãos que atendiam aos critérios de renda mínima previstos na Carta Magna Imperial poderiam exercer o voto em primeiro grau. A despeito disso, a participação política no período imperial era significativa se comparada com as eleições realizadas em outros países. ${ }^{13}$

Após serem realizadas as eleições de primeiro grau - também chamadas de eleições paroquiais - os eleitos tinham a tarefa de eleger os deputados e senadores que iriam compor o Legislativo brasileiro na chamada eleição de segundo grau ou de província. Para ser considerado eleitor da província era necessário ser eleitor de primeiro grau, além de não fazer parte do grupo dos libertos, criminosos pronunciados e também não ter renda líquida vinculada a comércio ou emprego.

Cumpre salientar que não eram todas as vagas do poder Legislativo escolhidas pelos cidadãos eleitores, visto existir o poder Moderador, conferido única e exclusivamente ao imperador, que detinha a prerrogativa da nomeação dos senadores em lista tríplice formada pelos mais votados. Fora isso, o imperador detinha prerrogativa de dissolver a Câmara dos Deputados, fato que ocorreu com alguma frequência no período imperial.

\footnotetext{
$\overline{12}$ Os artigos 91 e 92 da Constituição Imperial regulamentavam essa matéria, dispondo que: Têm voto nestas eleições primárias: I) Os cidadãos brasileiros, que estão no gozo de seus direitos políticos; II) os estrangeiros naturalizados" (Art. 91.), e que "Não possuem direito de votar: 1) Os menores de vinte e cinco anos, nos quais se não compreendem os casados, e oficiais militares, que forem maiores de vinte e um anos, os bacharéis formados, e clérigos de ordens sacras; II) os filhos-famílias que estiverem na companhia de seus pais, salvo de servirem ofícios públicos; III) Os criados de servir, em cuja classe não entram os guarda-livros, e primeiros-caixeiros das casas de comércios, os criados da Casa Imperial, que não forem de galão branco, e os administradores das fazendas rurais e fábricas; IV) os religiosos e quaisquer, que vivam em comunidade claustral; V) os que não tiverem de renda líquida anual cem mil réis por bens de raiz, indústria, comércio, ou emprego" (Art. 92).

${ }^{13}$ Segundo a observação de José Murilo de Carvalho: "Em 1872, os votantes chegaram a um milhão, o que correspondia a 13\% da população livre. A porcentagem subia para $53 \%$ da população masculina de 25 anos ou mais e $43 \%$ da mesma população de 20 anos ou mais. Estudos sobre a participação efetiva nas eleições confirmam esses dados. A participação era alta para a época, de vez que envolvia no exercício do voto metade da população adulta masculina (CARVALHO, 1996, p. 343).
} 


\subsubsection{Sistema Eleitoral da Primeira República Brasileira}

Após o fim da Monarquia imperialista em 1889, foi promulgada a primeira Constituição Federal brasileira em 1891, que instituiu inúmeras inovações eleitorais, entre as quais: foi definido o sistema de governo presidencialista, a forma de Estado Federativo e o sistema bicameral manteve-se no poder Legislativo, chamado agora de Congresso Nacional; foram alteradas as durações dos mandatos e foram redefinidos os requisitos para o exercício dos direitos políticos, com a extinção do voto censitário.

No âmbito do poder Executivo federal, o chefe era o presidente da República, sucedido pelo vice-presidente, eleitos simultaneamente para um mandato de 4 anos, sem a possibilidade de reeleição. Era utilizado o sistema majoritário absoluto, por meio do voto direto dos eleitores e, caso não fosse atingida a maioria necessária, o Congresso Nacional escolheria mediante a maioria dos presentes.

Já o poder Legislativo federal era composto pela Câmara dos Deputados e pelo Senado Federal, eleitos simultaneamente pelo território nacional para mandatos de 3 e 9 anos, respectivamente. 0 sistema eleitoral adotado para as eleições legislativas variou ao longo do tempo, não tendo previsão expressa na Constituição Federal de 1891. Sendo assim, ocorreram diversos desdobramentos do sistema eleitoral majoritário simples em leis esparsas.

Uma das particularidades do período inicial da República era a inexistência de partidos nacionais e de vinculação dos votos a candidatos determinados. Ou seja, o eleitor poderia votar em qualquer nome, independentemente se existia prévia inscrição.

Eram considerados eleitores os maiores de 21 anos, excluídas as condicionantes para casados, oficiais militares, bacharéis e clérigos de ordens sacras. Eram excluídos do direito ao voto os mendigos, os praças e os religiosos sujeitos ao voto de obediência. As mulheres ainda não possuíam esse direito, conforme elencado por Nicolau Jairo: "À maneira da Constituição do Império, a Carta de 1891 não vetava, em nenhum de seus artigos, o direito de voto para as mulheres. Não havia necessidade de fazê-lo, pois a política do século XIX era pensada como uma atividade eminentemente masculina" (NICOLAU, 2012, p. 28).

Além disso, foi extinto o voto censitário, e foi incluída a obrigatoriedade de não ser analfabeto para votar. Tal requisito limitou o avanço do eleitorado brasileiro por muitos anos em virtude do elevado contingente de analfabetos existentes no período da República Velha. E um dos institutos mais deletérios da história do Direito Eleitoral brasileiro surgiu com a Constituição Federal de 1891. Não existia nenhum instituto protetivo ao sigilo do voto e de possíveis fraudes, o que possibilitou o controle dos resultados eleitorais pela elite latifundiária, perpetuada na pessoa do coronel detentor dos meios de sobrevivência nas regiões menos abastadas. Isso levou à criação do chamado "voto de cabresto", em que o coronel possuía redutos eleitorais e os controlava por intermédio do abuso de autoridade, compra de votos ou a utilização da máquina pública para atingir as suas finalidades pessoais. ${ }^{14}$ Por isso mesmo, a República Velha ficou conhecida como o período do coronelismo e da baixa adesão da população nas votações, tendo em vista os incontáveis esforços, inclusive fraudulentos, para perenizar políticos em suas atribuições e a falta de participação maciça da população. ${ }^{15}$

A quebra dos paradigmas eleitorais cobertos de fraudes e baixa participação da população apenas ocorreu a partir de 1930 com o fim da República Velha e da instauração de institutos inovadores do Direito Eleitoral mundial.

\footnotetext{
${ }^{14}$ Acerca do fenômeno do coronelismo no Brasil, sua origem e pressupostos, ver: LEAL, 1949.

${ }^{15}$ A esse respeito, sustentou Jairo Nicolau que "a taxa de analfabetismo variava entre os Estados e era mais acentuada entre as mulheres, mas, para o ponto que nos interessa (definir o teto de adultos alistáveis), podemos dizer que cerca de dois terços dos adultos em idade de voto estavam excluídos do direito de voto. (...) O fato de o cidadão ter de voluntariamente requisitar sua inscrição (a partir de 1904) e a exigência de precisar apresentar uma série de documentos (a partir de 1916) provavelmente contribuíram para que uma parte dos eleitores não solicitasse o registro. Há de considerar, ainda, o papel das eleições no sistema representativo da Primeira República. Seja por conta das fraudes ou dos arranjos prévios entre os diversos grupos políticos, elas eram pouco competitivas. Nesse quadro, os indivíduos que não fossem vinculados a determinados grupos políticos não se sentiam motivados a coletar seus documentos e requisitar a inscrição como eleitor" (NICOLAU, 2012, p. 32).
} 


\section{Debate}

\subsubsection{As Mudanças no Sistema Eleitoral na Era Vargas}

Em 1930 iniciou-se um novo período para o Direito Eleitoral brasileiro. Popularmente conhecida como Era Vargas, o início desse período foi marcado pelo fechamento do poder Legislativo e pela avocação de suas atribuições pelo autoproclamado chefe do Executivo Federal, até que os trabalhos finais da Constituinte fossem finalizados. Esse foi o início de diversas mudanças eleitorais.

Com a promulgação da Constituição de 1934, uma das maiores inovações do sistema eleitoral brasileiro surgiu: a judicialização constitucional das eleições. A Justiça Eleitoral passou a ter previsão na Constituição e o procedimento das eleições federais, estaduais e municipais, bem como seus processos judiciais, foram centralizados em suas competências.

O prazo do mandato presidencial permaneceu em 4 anos para presidente da República e vice-presidente, sendo proibida a reeleição e a simultaneidade das eleições. Em contrapartida, o poder Legislativo Federal sofreu diversas alterações. Os integrantes da Câmara dos Deputados, na qual se reuniam os representantes do povo brasileiro, passaram a ter o mandato de 4 anos, eleitos mediante sistema proporcional. Já os senadores possuíam um mandato de 8 anos, com o Senado sendo composto pelos representantes dos Estados e do Distrito Federal.

As principais mudanças geradoras de evolução das eleições são atinentes aos direitos de sufrágio ativo e voto. As mulheres, pela primeira vez na História brasileira, consolidaram seus direitos eletivos por meio do Código Eleitoral de 1932 e a idade mínima para votar foi reduzida de 21 para 18 anos. Neste período surgiu, também, o voto obrigatório, fundamentado no temor de que uma participação não expressiva da população no processo eleitoral pudesse fragilizar a legitimidade das eleições (SOARES, 1973).

Foram criadas medidas para prevenir a possibilidade de fraudes durante a votação e na apuração. Foi instituído o gabinete indevassável, espaço particular para votar e as urnas eram lacradas logo após o encerramento da votação. Enfim, o voto no Brasil foi tornado universal, secreto, obrigatório, igual e direto, mas a proibição ao voto do analfabeto ainda perdurou durante a Era Vargas, o que afastava grande parte da população do processo eleitoral. ${ }^{16}$ Diante de todas essas alterações, viu-se uma grande evolução do sistema eleitoral brasileiro em caráter de representatividade, rotatividade, direito de votar, segurança e transparência das eleições, mas ocorreram também restrições impeditivas de aumento significativo da participação popular.

\subsection{Conceito e Características do Sistema Eleitoral}

Os sistemas eleitorais permitem a participação regrada e previamente determinada dos cidadãos no processo de escolha de seus representantes. Há basicamente três variações tradicionais dos sistemas eleitorais: majoritário, proporcional e misto. Cada um desses sistemas cumpre uma finalidade especifica na determinação das características do sistema político e partidário. Os sistemas majoritários visam a criar condições de governabilidade e previsibilidade no sistema político. Isso porque, com fundamento nesses sistemas eleitorais, a formação de maiorias partidárias torna-se mais simples, se não natural. Já os sistemas proporcionais têm como objetivo a criação de condições mais favoráveis para a representação de tendências políticas e grupos ideologicamente identificados. Em contrapartida, os sistemas proporcionais tendem a dificultar a formação de maiorias parlamentares, tendo em vista a multiplicação de agremiações partidárias com assento no Parlamento. ${ }^{17} \mathrm{O}$ Brasil, atualmente, aplica os sistemas majoritário e o proporcional.

\footnotetext{
${ }^{16}$ Esse aspecto foi duramente criticado por Manoel Rodrigues Ferreira, para quem: "No Brasil, durante 357 anos, o analfabeto teve o direito de votar. Desde a primeira eleição democrática, realizada por João Ramalho em São Vicente, a 22 de janeiro de 1532, até 15 de novembro de 1889, o analfabeto sempre pôde votar. Com a instauração da República é que foi abolida a extensão do voto ao analfabeto. Tal proibição era uma instituição relativamente nova no Brasil. Eu dizia então: ora, desde que se considera que o eleitorado alfabetizado sabe votar, que tem discernimento para escolher, então, seria lógico que esse eleitorado esclarecido deliberasse sobre a extensão do voto ao analfabeto num plebiscito nacional. Não parecia justo que só o Congresso Federal tivesse poderes para resolver esse problema. Nós, a massa dos eleitores, não estamos aptos a deliberar sobre problemas econômicos e financeiros e outras altas questões especializadas, que devem ser mesmo atribuições do Congresso. Mas assunto como aquele, todos nós, eleitores alfabetizados e esclarecidos, estávamos capacitados a resolver. Por que, então, não se realizou um plebiscito para dar a todos a oportunidade de opinar? Isto seria altamente democrático, pois possibilitaria aos eleitores participar da solução de um problema nacional" (FERREIRA, 2005, p. 326).

17 Trata-se, neste caso, de tendências geradas pelo sistema partidário. Não de causas necessárias e deterministas. A esse respeito, comentando e criticando a interpretação corrente das conhecidas Leis de Duverger, ver: SILVA, 1980, p. 289.
} 
O sistema majoritário possui como regra de determinação do resultado político a vontade da maioria dos votantes, subdividida em absoluta e relativa. A maioria absoluta visa à obtenção do primeiro número inteiro após a metade dos votos válidos, ou seja, a fração não pode ser considerada maioria absoluta. Já a maioria relativa não possui porcentagem mínima de obtenção de votos, mas considera eleito o candidato que alcançar o maior número de votos para o cargo que almeja. Esse sistema possui duas espécies, a de turno único e dois turnos, estritamente ligadas à maioria absoluta ou relativa. $O$ primeiro aplica-se nas eleições em que não há previsão de segundo turno, ou seja, é eleito o candidato que conseguir o maior número de votos, independentemente de número mínimo de votos.

A espécie majoritária de dois turnos, em contrapartida, apenas considera eleito o candidato que atingir a maioria absoluta dos votos válidos, excluídos os brancos e nulos. Caso isso não ocorra, são realizadas novas eleições com os dois candidatos mais votados. Nesta nova eleição considera-se eleito o que obtiver a maioria simples dos votos.

O sistema proporcional, comumente aplicado apenas nas eleições do Legislativo, objetiva gerar uma composição partidária tão fiel quanto possível do colorido partidário existente no território nacional, ${ }^{18}$ mas ele também tende a criar o fulgor pela multiplicidade partidária, na qual se desenvolvem diversas correntes ideológicas com ânsia de saciar a vontade de aplicabilidade no mundo político, momento em que gera a quebra na governabilidade e na real possibilidade de grande representatividade no Congresso Nacional. ${ }^{19}$

Diferentemente do sistema eleitoral majoritário, há diversas etapas a serem seguidas para determinar os candidatos aptos a disputar a eleição. Inicialmente, calcula-se o chamado quociente eleitoral, dividindo-se o número de votos válidos apurados pelo de lugares a preencher em cada circunscrição eleitoral disputada, desprezada a fração se igual ou inferior a meio, equivalente a um, se superior. Após, calcula-se o quociente partidário dividindo-se pelo quociente eleitoral o número de votos válidos obtidos sob a mesma legenda ou sob a coligação, desprezada a fração em qualquer hipótese. Com isso, obtém-se um número equivalente ao de representantes de cada partido eleito.

Ressalta-se que, no sistema brasileiro atual, é possível dirigir o voto ao candidato ou apenas na legenda, ressaltando-se que em ambos os casos o voto será contabilizado no quociente partidário do partido ao qual o candidato se encontra vinculado. Em virtude de recente mudança da lei eleitoral, os candidatos registrados devem obter votos nominais em número igual ou superior a $10 \%$ do quociente eleitoral para possuírem direito ao mandato.

É recorrente a hipótese em que os votos obtidos pelos partidos não preenchem, na integralidade, as cadeiras a serem representadas. Por isso, criou-se um sistema para as sobras eleitorais chamado de Sistema de Média. O sistema adotado no Direito brasileiro de maiores médias, considerando-se como maior média partidária a do partido que obtenha o maior quociente numérico após a divisão do número de votos a seu favor pelo quociente partidário mais um. Tal sistemática tem como objetivo reforçar as maiores bancadas que compõem o Parlamento. ${ }^{20}$ Cumpre esclarecer, no entanto, que mesmo na aplicação da sistemática de maiores médias, deve-se respeitar o mínimo de $10 \%$ do quociente eleitoral em votos nominais para os candidatos serem eleitos.

\subsection{Previsão Constitucional do Sistema Eleitoral Brasileiro}

A Constituição Federal de 1988 prevê um sistema eleitoral complexo, em que são combinadas diferentes sistemáticas de eleição para o preenchimento de vagas em diferentes cargos políticos. A sistemática majoritária possui previsão para aplicação tanto em sua forma absoluta de dois turnos como em sua forma simples ou relativa. Às eleições para prefeito, governador, presidente da República e os respectivos vices aplica-se, em

\footnotetext{
18 FERREIRA, 1989, p. 351.

${ }^{19}$ Eis a crítica realizada ao sistema proporcional, no pensamento de José Jairo Gomes: "O excesso de partidos políticos provoca instabilidade no poder, haja vista que fragmenta em demasia as forças políticas, impedindo a formação de maiorias sólidas e consistentes. Não contando com maioria no Parlamento, o governante é impelido a realizar inúmeros acordos - muitos deles inconfessáveis - para manter a governabilidade e a estabilidade política, de maneira a implantar as medidas e as políticas públicas entendidas como necessárias ou adequadas ao país. A história recente do Brasil revela a verdade dessa assertiva. Impende encontrar um ponto de equilíbrio, no qual a representação das minorias seja assegurada, mas também seja garantida a solidez das maiorias e, pois, a governabilidade (GOMES, 2016, p. 145).

${ }^{20}$ BONAVIDES, 2011.
} 
regra, o majoritário absoluto de dois turnos, todos para mandato de 4 anos. A única exceção é a eleição para prefeito em cidades com menos de 200 mil eleitores, quando se aplica sistemática majoritária de turno único. Fora isso, a Constituição possui previsão para a aplicação do sistema eleitoral majoritário simples nas eleições para senadores para mandato de 8 anos.

Aos deputados federais é aplicado o sistema proporcional para mandatos de 4 anos, mesmo período estabelecido para uma legislatura. Esta mesma sistemática é aplicada à eleição de vereadores, deputados estaduais e distritais, com fundamento no que dispõe o Código Eleitoral brasileiro.

\subsection{O Problema do Voto Obrigatório}

Para se falar em voto, há de se falar primeiramente em sufrágio. O sufrágio nada mais é que o direito público subjetivo, de natureza política, que possui o cidadão para eleger ou ser eleito, chamado também de sufrágio ativo e passivo (SILVA, 2014, p. 353). Tal direito possui restrições estabelecidas no artigo 14, sendo reconhecido o sufrágio ativo apenas aos brasileiros natos ou naturalizados, maiores de 16 anos, que não estejam conscritos (regime militar obrigatório) ou sejam estrangeiros. O voto é o exercício do sufrágio ativo, ou seja, é a efetiva participação da organização estatal pelo direito subjetivo atribuído aos cidadãos, sendo obrigatório aos maiores de 18 anos e menores de 70 (CF, artigo 14, parágrafo 1ㅇ, I) e facultativo aos analfabetos, maiores de 70 anos e maiores de 16 e menores de 18 anos (CF, artigo 14, parágrafo 1ㅇ, II). Nos termos da Constituição Federal, o voto possui as características de ser direto, livre, secreto, periódico, igual e obrigatório.

A questão que se coloca, então, é a seguinte: Como é possível compatibilizar as características do direito fundamental à participação política, exercida mediante o voto, com a obrigatoriedade do ato de votar? Estaríamos, neste caso, não diante de um direito subjetivo do cidadão, mas sim diante de um dever constitucional, vez que a Constituição não admite que os maiores de 18 e menores de 70 anos se abstenham do ato de votar? Enfim, como é possível compatibilizar essas características do voto, com a constatação de que o cidadão exerce, por meio deste ato, uma ação democrática, sendo que a democracia é um regime político fundado na liberdade? Os itens seguintes deste trabalho abordam essas questões.

\subsubsection{A Obrigatoriedade e sua Coercibilidade}

O voto obrigatório surgiu no Brasil no período da Era Vargas com a justificativa da necessidade de se manter a legitimidade de um governo ditatorial. Perpetuou-se no tempo, fundado em diversas outras justificativas. $^{21}$

Entre tais justificativas encontram-se: a imaturidade da "massa popular" para o voto facultativo; o cumprimento do dever social e político de desempenhar a função da soberania popular; a necessidade de grande participação eleitoral para dar legitimidade às eleições.

Dentro da obrigatoriedade existe a coercibilidade estatal no comparecimento ao local de votação. Ou seja, o cidadão não está devidamente obrigado a votar em alguém, mas sim em se apresentar e apor sua assinatura na folha individual de votação da seção eleitoral. Neste sentido, José Afonso da Silva, o voto somente se realiza com a efetiva escolha de um representante político, pois o eleitor que não desempenha tal função não cumpre o seu dever social e político (SILVA, 2014, p. 362).

Esta afirmação, porém, desconsidera as características básicas do voto. O eleitor é um sujeito de direitos, não um instrumento a ser manipulado pelo sistema político. Por isso, apenas considerar a necessidade da participação do eleitorado, como faz José Afonso da Silva, para disso retirar a fundamentação da obrigatoriedade do voto é, no mínimo, uma visão parcial e distorcida do Direito Constitucional, visto que o eleitor também possui o direito público subjetivo de manifestar seu descontentamento com os candidatos apresentados, e tal mister pode ser realizado por meio do voto branco, nulo ou pela abstenção. A obrigatoriedade do voto é uma forma de instrumentalização do direito fundamental e também uma ação paternalista do Estado, que considera ser possível impingir valores democráticos nos cidadãos, desconsiderando, com isso, que a verdadeira democracia é uma experiência contínua que se faz com erros e acertos dos titulares dos direitos

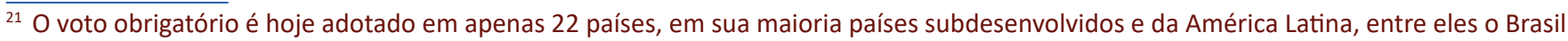


fundamentais. Negar a possibilidade de o cidadão se abster do exercício do voto, mesmo que este ato cause dano ao processo eleitoral, é adotar uma forma de perfeccionismo democrático, que pouco se diferencia da imposição totalitária de um modo de vida e de uma visão do mundo. ${ }^{22}$

Fora isso, não se compreende como a coercibilidade do exercício de um direito fundamental possa fomentar o desenvolvimento da consciência política dos cidadãos. O que ocorre, na verdade, é justamente o contrário. Os valores democráticos são criados em um ambiente que favoreça o exercício da liberdade, que deve estar relacionada com a percepção da responsabilidade que cada cidadão tem em relação aos seus atos. Ao se exigir que o voto seja necessariamente exercido, ocorre uma espécie de infantilização do cidadão, que se transforma em um objeto manipulado pelo sistema político eleitoral. Isso desvirtua completamente o sentido do desenvolvimento da educação democrática, que deve ser incentivada por meio de um processo de educação crítica voltada para a reflexão contínua a respeito do sentido da representação política na vida de cada um.

O voto obrigatório é um instrumento de coerção que desvirtua esse processo, vez que nega ao cidadão a possibilidade de exercer um juízo crítico a respeito do sistema político, fomentando, assim, a descrença na democracia representativa e retirando o valor do voto. ${ }^{23}$ Esse processo de degradação foi corretamente constatado por José Jairo Gomes, para quem os cidadãos obrigados a votar "votam, pois, em qualquer um, no primeiro que se apresenta ou no mais bem aparentado, isso quando não negociam seus votos, transformando-os em mercadoria, já que só comparecem às urnas compulsoriamente" (GOMES, 2016, p. 77).

A coercibilidade do voto é, portanto, um fator de desestabilização e degradação do processo democrático. Ela não tem criado interesse nos cidadãos em buscar candidatos idôneos e participar de forma sadia das eleições. Cria, ao contrário, o sentimento de insatisfação e desprezo pela vida política, sentimento que se agrava quando grande parte dos atores políticos são acusados de terem cometido delitos. Neste contexto, a busca inconsequente pela realização plena e absoluta da democracia, ideal que fundamenta a obrigatoriedade do voto, pode revelar-se como o princípio do fim do próprio regime democrático.

Enfim, sob o ângulo da dogmática dos direitos fundamentais, a coercibilidade no direito ao exercício do voto gera dúvidas no que diz respeito à concepção das características deste direito fundamental. Isso porque, de acordo com a formulação clássica, as normas constitucionais de garantia dos direitos fundamentais "servem, em primeira linha, para assegurar uma esfera de liberdade do indivíduo contra intervenções do poder público". ${ }^{24}$ Como conceber, então, que o voto seja uma obrigação imposta pelo Estado ao titular do direito fundamental? Existem teorias dos direitos fundamentais que igualam a estrutura normativa dos direitos e dos deveres fundamentais. Cite-se, como exemplo, as teorias institucional e dos valores dos direitos fundamentais, que instrumentalizam o conteúdo do direito, condicionando a sua proteção à busca de uma finalidade socialmente valiosa. ${ }^{25}$ Chamadas de teorias simétricas, essas orientações contemplam a possibilidade de uma equivalência estrutural entre os direitos e os deveres fundamentais, do que decorre a potencial inversão da proteção constitucional do direito em desfavor do indivíduo. Afinal, transformado em dever, o direito fundamental passa a ser a fonte de obrigações dirigidas ao seu próprio titular. E, assim, aquilo que antes era a proteção constitucional da liberdade torna-se um instrumento de reforço da autoridade.

\footnotetext{
$\overline{22}$ Nessa linha, criticando a visão paternalista dos direitos fundamentais, ver: KNIESEL e POSCHER, 2004.

${ }^{23}$ Segundo a legislação vigente o descumprimento da obrigação de comparecer no local de votação é passível de sanções severas, todas previstas no artigo 70, da Lei 4.737, de 1965: O eleitor que deixar de votar e não se justificar perante o juiz eleitoral até 30 (trinta) dias após a realização da eleição, incorrerá na multa de 3 (três) a 10 (dez) por cento sobre o salário-mínimo da região, imposta pelo juiz eleitoral e cobrada na forma prevista no artigo 367. $\S 1$ 10. Sem a prova de que votou na última eleição, pagou a respectiva multa ou de que se justificou devidamente, não poderá o eleitor: I - inscrever-se em concurso ou prova para cargo ou função pública, investir-se ou empossarse neles; II - receber vencimentos, remuneração, salário ou proventos de função ou emprego público, autárquico ou paraestatal, bem como fundações governamentais, empresas, institutos e sociedades de qualquer natureza, mantidas ou subvencionadas pelo governo ou que exerçam serviço público delegado, correspondentes ao segundo mês subsequente ao da eleição; III - participar de concorrência pública ou administrativa da União, dos Estados, dos Territórios, do Distrito Federal ou dos Municípios, ou das respectivas autarquias; IV - obter empréstimos nas autarquias, sociedades de economia mista, caixas econômicas federais ou estaduais, nos institutos e caixas de previdência social, bem como em qualquer estabelecimento de crédito mantido pelo governo, ou de cuja administração este participe, e com essas entidades celebrar contratos; $\mathrm{V}$ - obter passaporte ou carteira de identidade; VI - renovar matrícula em estabelecimento de ensino oficial ou fiscalizado pelo governo; VII - praticar qualquer ato para o qual se exija quitação do serviço militar ou imposto de renda.

${ }^{24}$ BVerfGE 7, 198 - Lüth.

${ }^{25}$ A esse respeito, ver a crítica contundente de Ernst W. Böckenförde em: BÖCKENFÖRDE, 1991.
} 
É fácil constatar a deformação da dogmática dos direitos fundamentais operada por essa compreensão. Transformados em deveres, os direitos fundamentais não podem ser mais vistos como normas vinculadas à ligação da liberdade, quanto menos exigem eles uma abstenção estatal para a sua realização. Deveres e obrigações, os direitos fundamentais exigem, não só do Estado, mas também do indivíduo, a persecução de finalidades e a realização de ações voltadas para esses fins. ${ }^{26}$ É justamente isso o que ocorre com o direito ao voto, que no Direito Constitucional brasileiro deixou de ser uma simples faculdade garantida pela Constituição Federal para se tornar uma obrigação, destinada a realizar um fim que está acima da vontade do cidadão.

Apresentadas as críticas à imposição constitucional do dever de votar, cumpre agora verificar como os problemas apontados podem ser solucionados. E, neste ponto, a solução não pode ser outra senão a extinção do voto obrigatório .

\subsection{Voto Obrigatório e Cláusulas Pétreas}

O voto está contemplado na Constituição Federal de 1988 entre os direitos fundamentais estabelecidos. Nem todas os aspectos do voto, contudo, são considerados cláusula pétrea. É preciso, então, dissecar a possibilidade de uma mudança constitucional de diversas características do voto, entre elas a obrigatoriedade. $\mathrm{O}$ artigo 60 estabelece os requisitos para a Emenda Constitucional ser aprovada, entre eles a impossibilidade de abolir determinados direitos. E em seu parágrafo 4으, inciso II, encontra-se a menção ao voto. Segundo tal dispositivo, não é passível de deliberação a emenda tendente a abolir "o voto direto, secreto, universal e periódico". Entre as características pétreas do voto encontra-se o voto direto, secreto, universal e periódico, expressamente considerado cláusula pétrea e impossível de se abolir.

A Emenda Constitucional que tenda a abolir tais características do voto pode ser considerada inconstitucional desde o momento de sua proposta, sendo inclusive possível a realização do assim denominado controle de constitucionalidade preventivo indireto, realizado pela via da interposição de mandado de segurança impetrado por parlamentar, ${ }^{27}$ o que não afasta a possibilidade de se realizar também o controle político pela via parlamentar, ou o repressivo de natureza judicial.

De toda forma, as matérias que integram o núcleo imutável da Constituição devem ser interpretadas restritivamente, sob pena de tornar todo o texto constitucional petrificado, forçando, com isso, a manifestação do poder constituinte originário. Sendo assim, é perceptível que o texto constitucional impede a mudança de certas características do voto e que, entre esses atributos, não se encontra o voto obrigatório. Abre-se, portanto, a possibilidade de se aprovar uma Emenda Constitucional no sentido de abolir a obrigatoriedade, sem que isso implique desrespeito às cláusulas pétreas.

De acordo com a jurisprudência do STF, no entanto, as emendas constitucionais que alterem o processo eleitoral estão englobadas pelo princípio da anualidade eleitoral, princípio garantido pelo artigo 16 da Constituição Federal de 1988. Para fins desta pesquisa, pode-se considerar como integrantes do processo eleitoral todo o desenvolvimento, sucessão e evolução de atos eleitorais que visam a elucidar a vontade da massa popular nas eleições, capazes de alterar os resultados das urnas. ${ }^{28}$ Não restam, portanto, dúvidas de que a alteração do voto obrigatório para facultativo resultaria em possíveis mudanças drásticas no processo eleitoral, pois afetaria aspectos relevantes da disputa política por votos, modificando inclusive a forma de organização das eleições e prospectiva de quantitativos de participação em geral.

De tudo isso conclui-se, então, ser possível abolir o voto obrigatório, pois não há restrições constitucionais que impeçam essa medida. Tal medida, contudo, deve obedecer o procedimento regular de uma Emenda Constitucional e, assim como as demais mudanças no processo eleitoral, deve respeito ao princípio da anualidade eleitoral.

\footnotetext{
${ }_{26}$ Para uma crítica sistemática de tal visão, ver: RANDERLZHOFER, 2006, p. 618.

${ }^{27}$ A esse respeito, ver: FERRAZ, 1999, p. 292.

${ }^{28} \mathrm{Na}$ formulação do Supremo Tribunal Federal, o processo eleitoral é considerado um direito fundamental e "representa garantia individual do cidadão-eleitor, detentor originário do poder exercido pelos representantes eleitos" (ADI 3.685, rel. Min. Ellen Gracie).
} 


\subsection{Uma Proposta de Instituição do Voto Facultativo}

Para alterar o voto obrigatório, conforme supramencionado, é necessária a aprovação de uma Emenda Constitucional. Essa é uma possibilidade real não só sob o prisma da ciência política, mas também sob o aspecto político. Hoje não só os sociólogos e os cientistas sociais os apoiadores do voto facultativo. Juristas e ministros também têm trilhado esse caminho. Representativo de tal linha evolutiva, Marco Aurélio de Mello afirmou que:

É hora de avançarmos e pensarmos no voto facultativo, deixando de tratar os cidadãos brasileiros como tutelados. A mudança também mudará o comportamento da classe política, estimulando-a a ter um desempenho à altura, para que o eleitor se sinta motivado a votar. Além disso, a busca de votos seria diferente, o esforço dos candidatos se daria no atacado, e não no varejo, reduzindo-se a chance da compra de votos ou do voto de "cabresto". 29

No âmbito legislativo já existem propostas neste sentido. Cite-se, como exemplo, a PEC 61/2016, de autoria principal da senadora Ana Amélia. O texto-base desta Proposta de Emenda Constitucional visa a alterar o artigo 14 da Constituição Federal e obter o resultado útil de tornar o voto facultativo em todo o território nacional. Saliente-se que, uma vez aprovada tal alteração, apenas o voto será tornado facultativo, mantendo-se o alistamento eleitoral obrigatório. Para fins práticos, o eleitor ainda seria obrigado comparecer ao cartório eleitoral para realizar seu alistamento e manter seu título eleitoral atualizado, mas poderia abster-se de comparecer no local de votação no dia da eleição, sem quaisquer sanções.

A justificativa apresentada pela autora da PEC 61 para a continuidade do alistamento eleitoral é a possibilidade de abstenções acidental, sem premeditação ou manifestação política, conforme se extrai da seguinte passagem da fundamentação da Proposta de Emenda:

O alistamento obrigatório amplia o grau de liberdade dos eleitores, mantendo abertas até o dia da votação as possibilidades de comparecimento e de não comparecimento. $O$ alistamento facultativo exige duas decisões do eleitor e pode, pela inércia passada, impedir eleitores de comparecer à votação por razões não políticas. Haveria um absenteísmo automático, não reflexivo, danoso para o processo democrático.

É perceptível o apoio existente para o voto facultativo instalar-se no Brasil, pois a mencionada Proposta de Emenda Constitucional atingiu o número de apoio mínimo dos senadores requisitado pela Constituição Federal - um terço dos membros do Senado Federal - e hoje encontra-se em tramitação. A PEC encontra-se na Comissão de Constituição, Justiça e Cidadania (CCJ) do Senado e ainda está no aguardo da designação do relator para a continuidade de seus trâmites internos.

Há de se informar ainda acerca da existência de outras diversas propostas no mesmo sentido, posteriores e anteriores, o que revela a manifesta vontade de alteração da Constituição Federal para tornar o voto facultativo.

Os representantes do povo e dos Estados, deputados e senadores respectivamente, via de regra devem manifestar o interesse popular e a melhor maneira de satisfazer os anseios gerais. Dito isto, as crescentes tentativas de se alterar a Constituição Federal maximizam a soberania popular de se ter a obrigatoriedade do voto fora da realidade brasileira.

Ademais, a situação política vivenciada no Brasil demonstra a insatisfação popular com a classe política existente. Essa insatisfação vem sendo exteriorizada no momento das votações, tendo em vista as eleições presidenciais de 2018 - utilizada como parâmetro pela possível capacidade de mensurar em âmbito nacional - em que o número de abstenções e votos brancos e nulos ultrapassa $20 \%$ do eleitorado brasileiro, número que tem aumentado conforme o decorrer dos anos. A tendência buscada pela facultatividade do voto é a evolução da base democrática brasileira, pela junção entre o fiel exercício dos direitos políticos, exercidos em um ato liberdade de escolha nas eleições, e a ação dos políticos em buscar de formas lícitas a maior participação eleitoral.

${ }^{29}$ Entrevista do presidente do TSE ao jornal O Globo, disponível em: https://m.oglobo.globo.com/opiniao/sim-ao-voto-facultativo-13412865 


\section{CONCLUSÕES}

Não está clara a razão da manutenção do voto obrigatório no Brasil. Instituto de origem fascista, essa obrigatoriedade é hoje paradoxalmente defendida por constitucionalistas e juristas de orientação democrática. A justificativa para isso é sempre: na condição de valor fundamental, a democracia deve ser defendida, ainda que isso implique uma afronta à liberdade e ao direito de escolha do eleitor. Esta pesquisa evidenciou que a manutenção do voto obrigatório no Brasil perpetua a tradição paternalista e autoritária do Estado brasileiro.

Em contrapartida, a maioria dos países existentes adotam o voto facultativo, inclusive países considerados extremistas em suas ações e legislação-base, mas que ofertam o integral exercício do direito ao voto aos seus cidadãos. Dessa forma, o direito à liberdade de expressão no voto possui expressiva restrição estatal no momento em que não é conferido ao cidadão votante o direito de permanecer inerte em relação às eleições, sejam elas municipais, estaduais, federais ou presidenciais.

Ao aplicar ao cidadão sanções e imposições de obrigatoriedade de participação eleitoral, o constituinte originário não forneceu o pleno exercício da liberdade de direito ao voto, assemelhando-se muito a uma condução coercitiva do cidadão até o local das urnas. No contexto atual, a continuidade do voto obrigatório apenas irá degradar a política brasileira e sua permanência sadia, pois todos os fatores indicam uma degradação e ruptura da ligação entre o povo e as eleições e criará uma disparidade entre os interessados em ingressar na vida política - sejam eles com boas intenções, ou malfeitores - e os cidadãos votantes, condição prejudicial à evolução eleitoral da atual crise vivenciada.

\section{REFERÊNCIAS}

BÖCKENFÖRDE, Ernst-W. “Grundrechtstheorie und Grundrechtsinterpretation”. In: Id., Staat, Verfassung, Demokratie, Frankfurt am Main: Surkamp, 1991.

BONAVIDES, Paulo. Curso de direito constitucional. 13. ed. São Paulo: Malheiros, 2003.

BONAVIDES, Paulo. Ciência política. São Paulo: Malheiros, 2011.

CARVALHO, José Murilo de. Cidadania no Brasil. O longo Caminho. 3. ed. Rio de Janeiro: Civilização Brasileira, 2002.

CASIELLO, Juan. Derecho Constitucional Argentino. Buenos Aires: Editorial Perrot, 1954.

CORWIN, Edward. A constituição norte-americana e seu significado atual. Rio de Janeiro: Jorge Zahar, 1978.

FERRAZ, Ana Cândida Cunha. Notas sobre o controle preventivo de constitucionalidade. Revista de Informação Legislativa, n. 36, p. 279-296, 1999.

FERREIRA, Manoel Rodrigues. A evolução do Sistema Eleitoral Brasileiro, 2. ed. Brasília: Secretaria de Documentação e Informação do Tribunal Superior Eleitoral, 2005.

FERREIRA, Pinto. Comentários à Constituição Brasileira, São Paulo: Saraiva, 1989. V. 1.

FERREIRA, Pinto. Direito constitucional moderno. São Paulo: Revista dos tribunais, 1971. V. II.

GOMES, José Jairo. Direito Eleitoral. 12. ed. São Paulo: Atlas, 2016.

HESSE, Konrad. Elementos de direito constitucional da República Federal da Alemanha. Porto Alegre: Sergio Antônio Fabris, 1998. KNIESEL, Michael; POSCHER, Ralf. “Die Entwicklung des Versammlungsrecht 2000 bis 2003”, NJW, p. 422-429, 2004.

LAURENTIIS, Lucas Catib. Vinculação e liberdade dos representantes políticos: entre mandato imperativo e representativo. Revista da Faculdade Mineira de Direito, v. 12, n. 23, p. 5-21, jan./jun. 2011.

LEAL, Vitor Nunes. Coronelismo, enxada e voto. Rio de Janeiro: Forense, 1949.

MENDES, Gilmar Ferreira. Direito Constitucional. São Paulo: Saraiva, 2015.

MIRANDA, Jorge. Teoria do Estado e da Constituição. Rio de Janeiro: Forense, 2007.

NICOLAU, Jairo Marconi. Eleições no Brasil: do Império aos dias atuais. 1. ed. São Paulo: Editora Zahar, 2012.

RAMAYANA, Marcos. Direito eleitoral. Rio de Janeiro: Impetus, 2010.

RANDELZHOFER, Albrecht. Grundrechte und Grundpflichten. In: MERTEN, Detlef; PAPIER, Hans-Jürgen (Herausg.). Handbuch der Grundrechte. München: CF Müller, 2006. p. 595-625.

SCHWARTZ, Bernard. Direito Constitucional Americano. Tradução Carlos Nayfeld, Rio de Janeiro: Forense Rio, 1966.

SILVA, José Afonso. Direito Constitucional Positivo. São Paulo: Malheiros, 2014

SOARES, G. A. D. Sociedade e política no Brasil. São Paulo: Difel, 1973.

SILVA, José Afonso. "Partidos políticos e sistemas eleitorais: o caso brasileiro. RPGE, n. 17, p. 287 et seq., dez. 1980.

SILVA, Luís Virgílio Afonso da Silva. Sistemas Eleitorais. São Paulo: Malheiros Editores, 1999.

SOLA, Juan Vicente. Manual de Derecho Constitucional. 1. ed. Buenos Aires: La Ley, 2010. 688p. 